Western University

Scholarship@Western

Aboriginal Policy Research Consortium International (APRCi)

$3-15-2010$

\title{
The prevalence and causes of vision loss in Indigenous Australians: the National Indigenous Eye Health Survey
}

Hugh R. Taylor

Jing Xie

Sarah Fox

Ross A. Dunn

Anna-Lena Arnold

See next page for additional authors

Follow this and additional works at: https://ir.lib.uwo.ca/aprci

Part of the Optometry Commons, and the Other Public Health Commons

Citation of this paper:

Taylor, Hugh R.; Xie, Jing; Fox, Sarah; Dunn, Ross A.; Arnold, Anna-Lena; and Keeffe, Jill E., "The prevalence and causes of vision loss in Indigenous Australians: the National Indigenous Eye Health Survey" (2010). Aboriginal Policy Research Consortium International (APRCi). 323.

https://ir.lib.uwo.ca/aprci/323 
Authors

Hugh R. Taylor, Jing Xie, Sarah Fox, Ross A. Dunn, Anna-Lena Arnold, and Jill E. Keeffe 


\title{
The prevalence and causes of vision loss in Indigenous Australians: the National Indigenous Eye Health Survey
}

\author{
Hugh R Taylor, Jing Xie, Sarah Fox, Ross A Dunn, Anna-Lena Arnold and Jill E Keeffe
}

\begin{abstract}
T n 1980, the National Trachoma and Eye Health Program (NTEHP) gave the first national data on eye health and vision loss in Australian Aboriginal and Torres Strait Islander peoples. ${ }^{1}$ At that time, rates of blindness in Indigenous Australians were 10 times higher than in other Australians, which is a striking paradox, as Aboriginal people have the best recorded visual acuity. 2,3

There have been several national programs to improve the delivery of eye care to Indigenous Australians, ${ }^{4-6}$ and there are ongoing efforts by committed individuals and groups. Occasional reports underscore the ongoing presence of trachoma and the dramatic increase in diabetic eye disease..$^{7-13}$ However, since the 1980 report, there have been no further national surveys on the status of Indigenous eye health to assess the adequacy of current services and for future planning.

We report the results of a national population-based survey of vision and eye health in Indigenous children and older adults performed in 2008. It redefines the gap in eye health between Indigenous and other Australians.
\end{abstract}

\section{METHODS}

\section{Sample selection}

Data from the June 2006 national census were used to delineate 30 geographic areas that each included about 300 Indigenous people. ${ }^{14}$ The sampling method has been described in detail elsewhere. ${ }^{15}$ Data collection was undertaken in 2008.

\section{Sample size}

The sample size was determined to detect a doubling in the rate of presenting vision impairment in Indigenous Australians compared with the rate in the Australian population as a whole ("mainstream" Australia). Rates of vision impairment in mainstream Australia have been reported as $4.2 \%$ for the better eye in adults ${ }^{16}$ and $5 \%$ in the worse eye for 12-year-old children. ${ }^{17}$

Sample sites were selected using the Australian Indigenous Geographical Classification. The classification is based on census collection districts, which are aggregated into Indigenous Locations, which in turn are

\section{ABSTRACT}

Aim: To determine the prevalence and causes of vision loss in Indigenous Australians. Design, setting and participants: A national, stratified, random cluster sample was drawn from 30 communities across Australia that each included about 300 Indigenous people of all ages. A sample of non-Indigenous adults aged $\geqslant 40$ years was also tested at several remote sites for comparison. Participants were examined using a standardised protocol that included a questionnaire (self-administered or completed with the help of field staff), visual acuity (VA) testing on presentation and after correction, visual field testing, trachoma grading, and fundus and lens photography. The data were collected in 2008.

Main outcome measures: VA; prevalence of low vision and blindness; causes of vision loss; rates of vision loss in Indigenous compared with non-Indigenous adults.

Results: 1694 Indigenous children and 1189 Indigenous adults were examined, representing recruitment rates of $84 \%$ for children aged $5-15$ years and $72 \%$ for adults aged $\geqslant 40$ years. Rates of low vision (VA $<6 / 12$ to $\geqslant 6 / 60)$ were $1.5 \%(95 \% \mathrm{Cl}, 0.9 \%-2.1 \%$ ) in children and $9.4 \%(95 \% \mathrm{Cl}, 7.8 \%-11.1 \%)$ in adults. Rates of blindness ( $\mathrm{VA}<6 / 60)$ were $0.2 \%(95 \% \mathrm{Cl}, 0.04 \%-0.5 \%)$ in children and $1.9 \%(95 \% \mathrm{Cl}, 1.1 \%-2.6 \%)$ in adults. The principal cause of low vision in both adults and children was refractive error. The principal causes of blindness in adults were cataract, refractive error and optic atrophy. Relative risks (RRs) of vision loss and blindness in Indigenous adults compared with adults in the mainstream Australian population were 2.8 and 6.2, respectively. By contrast, RRs of vision loss and blindness in Indigenous children compared with mainstream children were 0.2 and 0.6 , respectively.

Conclusion: Many causes of vision loss in our sample were readily avoidable. Better allocation of services and resources is required to give all Australians equal access to eye health services.

MJA 2010; 192: 312-318

combined into Indigenous Areas and then Indigenous Regions (each of these categories comprising a progressively larger geographical area). Indigenous Areas were grouped according to the Accessibility/Remoteness Index of Australia into five strata: major city, inner regional, outer regional, remote and very remote. The very remote stratum was divided into very remote coastal and very remote inland. Within each stratum, five sample areas were randomly selected (with probability of selection being proportional to community size and some smaller communities being combined to make a larger group) to yield geographic areas containing about 300 Indigenous people.

\section{Recruitment}

The survey team worked with existing Aboriginal Medical Services and community members. Promotional material included word of mouth, telephone calls, posters, flyers, radio messages and local media.
An informal census was undertaken using all available community data to establish the size of the eligible population of Indigenous adults and children. Sources included community and local council housing lists, health service and hospital lists, Aboriginal housing or legal aid records, and local informants.

At the completion of the eye examination, children were given a pair of sunglasses and adults were given a pair of reading glasses.

\section{Examination procedures}

Standardised demographic data were collected by means of a written questionnaire (self-administered or completed with the help of field staff and an interpreter if necessary). ${ }^{18-20}$ A standardised eye examination was carried out on all participants. This included measurement of distance and near presenting visual acuity (VA), ${ }^{19,21}$ pinhole testing if VA was $<6 / 12$, or autorefraction and testing with correction if indicated, and visual 
field assessment with a Humphrey frequency doubling technology (FDT) test (Zeiss, Jena, Germany). Appropriate arrangements were made for treatment or referral.

All participants with VA of $<6 / 12$ were defined as having vision impairment. VA of $<6 / 12$ but $\geqslant 6 / 60$ was defined as low vision, and VA $<6 / 60$ as blindness. Vision impairment was attributed to refractive error when VA improved to $\geqslant 6 / 12$ with either the pinhole test or after refraction.

Trachoma was graded in each eye, using a $\times 2.5$ magnifying loupe, according to the World Health Organization simplified grading system. ${ }^{22}$ Digital photographs of the everted left tarsus were graded independently. $^{23}$

Fundal photographs of each eye were taken using a Canon CR-DGi retinal camera (Canon, Tokyo, Japan). Anteriorly focused, retroillumination photographs of the lens were taken in eyes with VA of $<6 / 12$ to assess cataract. ${ }^{24}$ Pupil-dilating drops were used when needed. Retinal photographs were assessed in a masked fashion (ie, with the grader blinded to the clinical condition or previous clinical grading of the patient) for diabetic retinopathy, ${ }^{25}$ macular changes $^{26}$ or optic disc cupping. ${ }^{27}$

A diagnosis of glaucoma was made if the cup-to-disc ratio (CDR) (ie, the ratio comparing the diameter of the "cup" portion of the optic disc with the total diameter of the optic disc) was greater than 0.8 or if two or more points on FDT testing were missed in an eye with a CDR of greater than 0.7. 19,28 To determine the distribution of optic disc diameters and CDRs in Indigenous Australians, 816 consecutive optic disc photographs were measured (data not presented here): 0.7 was 2 SD from the mean and 0.9 was 3 SD from the mean. ${ }^{29}$

\section{Non-Indigenous sample}

As population-based data on eye health for non-Indigenous Australians in remote areas were not available, a sample of non-Indigenous adults aged 40 years and over was sought at six remote sites. However, in two of the selected sites, the Aboriginal Medical Service considered it inappropriate to also examine non-Indigenous subjects. The size of each site was adjusted by adding or deleting adjacent census collection districts until it included 300-400 non-Indigenous adults. The recruitment and examination protocol for non-Indigenous people was the same as the protocol for Indigenous people.

\section{Data analysis}

Data were entered into an electronic database using Access 2000 (Microsoft Corp, Redmond, Wash, USA). For categorical variables, the $\chi^{2}$ test was used to test for significant differences in participants' characteristics by group. For continuous variables, significant differences between strata were evaluated by the Mann-Whitney-Wilcoxon test or Student $t$-test. $P$ values of $<0.05$ were taken to indicate statistical significance. All statistical analysis was done using STATA software, version 10.2 (Stata Corporation, College Station, Tex, USA).

\section{Ethics approval}

Primary ethics approval was obtained from the Human Research Ethics Committee of the Royal Victorian Eye and Ear Hospital. However, separate formal ethics approval was also required and obtained from the human research ethics committees of the Aboriginal Health and Medical Research Council of New South Wales, the Aboriginal Health Council of South Australia, the Menzies School of Health Research and the Australian Capital Territory Department of Health (approved 12 November 2007), as well as the Central Australian Human Research Ethics Committee, the Western Australian Aboriginal Health Information and Ethics Committee, the Tasmanian Scientific Research Advisory Committee, the Tasmanian Health and Medical Human Research Ethics Committee and the Queensland Aboriginal and Islander Health Council.

The protocol was also reviewed and approved by the board of the National Aboriginal Community Controlled Health Organisation and the appropriate organisation in each community. Permission was obtained as needed at the local, regional or state level to examine children in schools. Our research was conducted in accordance with the tenets of the Declaration of Helsinki as revised in 2000. Written, informed consent was obtained for all participants before examination.

\section{RESULTS}

The target population included 2007 Indigenous children and 1655 adults. Of these, 1694 children (84.4\%) and 1189 adults (71.8\%) were examined (Box 1). Of 163 non-Indigenous adults in four communities, $136(83.4 \%)$ were examined.

Additionally, in 26 communities, 402 Indigenous children who lived outside the sample area (and were thus ineligible for the study) were examined, as were 425 ineligible adults in 19 communities. Children living within or outside the sample area were generally similar demographically, although the ineligible children were more likely to speak English (Box 2). The ineligible adults differed in several ways from adults in the sample, reflecting self-selection for an eye examination.

Distance VA data on presentation were missing for six children and six Indigenous adults, all of whom were believed to have normal vision. Near VA data were missing for 12 Indigenous adults and one nonIndigenous adult.

Retinal images were available for 1057/ 1189 Indigenous adults (89\%) and 132/136 non-Indigenous adults (97\%). Photographs were gradable for both eyes in $82 \%$ of participants, gradable for one eye and partially gradable for the other in $7 \%$, and partially gradable for both eyes in 5\%. FDT test results were obtained for 1136 Indige-

\section{Age distribution of participants in the National Indigenous Eye Health Survey}

\begin{tabular}{|c|c|c|}
\hline $\begin{array}{l}\text { Age group } \\
\text { (years) }\end{array}$ & $\begin{array}{l}\text { Indigenous } \\
\text { children }\end{array}$ & \\
\hline 5 & 154 & \\
\hline 6 & 166 & \\
\hline 7 & 185 & \\
\hline 8 & 198 & \\
\hline 9 & 180 & \\
\hline 10 & 172 & \\
\hline 11 & 164 & \\
\hline 12 & 174 & \\
\hline 13 & 121 & \\
\hline 14 & 111 & \\
\hline 15 & 69 & \\
\hline Total & 1694 & \\
\hline $\begin{array}{l}\text { Age group } \\
\text { (years) }\end{array}$ & $\begin{array}{l}\text { Indigenous } \\
\text { adults }\end{array}$ & $\begin{array}{l}\text { Non-Indigenous } \\
\text { adults }\end{array}$ \\
\hline $40-44$ & 255 & 19 \\
\hline $45-49$ & 252 & 23 \\
\hline $50-54$ & 235 & 30 \\
\hline 55-59 & 166 & 11 \\
\hline $60-64$ & 118 & 17 \\
\hline 65-69 & 81 & 14 \\
\hline $70-74$ & 45 & 8 \\
\hline 75-79 & 22 & 6 \\
\hline 80-84 & 12 & 6 \\
\hline 85-89 & 3 & 2 \\
\hline Total & 1189 & 136 \\
\hline
\end{tabular}




\section{Demographic characteristics of participants in the National Indigenous Eye Health Survey*}

\begin{tabular}{|c|c|c|c|c|c|c|c|c|c|c|c|}
\hline \multirow[b]{2}{*}{ Characteristic } & \multicolumn{4}{|c|}{ Indigenous children } & \multicolumn{4}{|c|}{ Indigenous adults } & \multicolumn{3}{|c|}{ Non-Indigenous adults } \\
\hline & $\begin{array}{c}\text { Eligible } \\
(n=1694)\end{array}$ & $\begin{array}{l}\text { Ineligible } \\
(n=402)\end{array}$ & $\chi^{2 \text { (or }} z^{\dagger)}$ & $P$ & $\begin{array}{l}\text { Eligible } \\
(n=1189)\end{array}$ & $\begin{array}{c}\text { Ineligible } \\
(n=425)\end{array}$ & $\chi^{2}$ & $P$ & $\begin{array}{l}\text { Eligible } \\
(n=136)\end{array}$ & $\chi^{2 \ddagger}$ & $P^{\ddagger}$ \\
\hline Female & $49 \%$ & $49 \%$ & 0.007 & 0.94 & $61 \%$ & $59 \%$ & 0.30 & 0.58 & $62 \%$ & 0.05 & 0.83 \\
\hline Median age in years $(\mathrm{IQR})^{\S}$ & $9(7-12)$ & $9(7-12)$ & $-1.26^{\dagger}$ & 0.21 & $51(45-59)$ & $52(47-60)$ & $1.71^{\dagger}$ & 0.08 & $54(48-66)$ & $-3.73^{\dagger}$ & $<0.001$ \\
\hline English spoken at home & $66 \%$ & $52 \%$ & 25.8 & $<0.01$ & $59 \%$ & $75 \%$ & 33.9 & $<0.001$ & $97 \%$ & 76.1 & $<0.001$ \\
\hline $\begin{array}{l}\text { Education higher than } \\
\text { secondary school level }\end{array}$ & na & na & na & na & $12 \%$ & $18 \%$ & 142.4 & $<0.001$ & $20 \%$ & 26.3 & 0.001 \\
\hline Self-reported diabetes & $1.3 \%$ & $0.5 \%$ & 1.80 & 0.18 & $37 \%$ & $37 \%$ & 7.51 & 0.006 & $12 \%$ & 35.4 & 0.001 \\
\hline Current smoker & na & na & na & na & $67 \%$ & $60 \%$ & 0.01 & 0.92 & $57 \%$ & 4.57 & 0.03 \\
\hline History of eye problems & $19 \%$ & $20 \%$ & 0.15 & 0.70 & $78 \%$ & $84 \%$ & 5.38 & 0.02 & $84 \%$ & 1.93 & 0.17 \\
\hline Distance glasses normally worn & $8 \%$ & $7 \%$ & 0.64 & 0.42 & $26 \%$ & $32 \%$ & 4.99 & 0.03 & $49 \%$ & 31.0 & $<0.001$ \\
\hline Reading glasses normally worn & na & na & na & na & $61 \%$ & $68 \%$ & 5.16 & 0.02 & $74 \%$ & 8.97 & 0.003 \\
\hline
\end{tabular}

nous adults (96\%) and for all non-Indigenous adults. Trachoma grading was available for $98 \%$ of participants.

Ninety-six per cent of responses to questionnaire items were complete.

\section{Visual acuity on presentation}

For both children and adults, there were no statistically significant differences in presenting binocular distance vision between eligible and ineligible groups $\left(\chi^{2}\right.$ test $P$ values were between 0.3 and 0.9) (Box 3).
Overall, $1.5 \%$ of eligible Indigenous children had low vision $(\mathrm{VA}<6 / 12)$ and $0.2 \%$ were blind $(\mathrm{VA}<6 / 60)$. Of the eligible Indigenous adults, $9.4 \%$ had low vision and $1.9 \%$ were blind.

Rates of vision loss were weighted for the sampling rate from different strata. Weighted rates for eligible Indigenous children were $2.0 \%$ (95\% CI, 1.3\%-2.9\%) for low vision and $0.2 \%$ (95\% CI, 0.01\%-0.7\%) for blindness. Weighted rates for eligible Indigenous adults were $8.6 \%(95 \% \mathrm{CI}$,
$6.9 \%-10.7 \%)$ for low vision and $1.8 \%$ (95\% CI, $0.1 \%-3.3 \%$ ) for blindness.

Rates of blindness in eligible Indigenous adults and children did not vary significantly by state or remoteness category. Rates of low vision in adults tended to be lower in major city and regional areas (range, 6.6\%-7.8\%) than in remote and very remote areas (range, $9.5 \%-12.7 \%)$, but the difference was not statistically significant $\left(\chi^{2}=8.3 ; \quad P=0.60\right)$. However, the opposite was true in children. Compared with children in major cities,

\section{Binocular presenting distant visual acuity among participants in the National Indigenous Eye Health Survey*}

\begin{tabular}{|c|c|c|c|c|c|}
\hline \multirow[b]{2}{*}{$\begin{array}{l}\text { Presenting distant visual } \\
\text { acuity }\end{array}$} & \multicolumn{2}{|c|}{ Eligible Indigenous } & \multicolumn{2}{|c|}{ Ineligible Indigenous } & \multirow[b]{2}{*}{$\begin{array}{l}\text { Non-Indigenous } \\
\text { adults }(n=136)\end{array}$} \\
\hline & Children $(n=1694)$ & Adults $(n=1189)$ & Children $(n=402)$ & Adults $(n=425)$ & \\
\hline $\begin{array}{l}\text { Normal vision } \\
(V A \geqslant 6 / 12)\end{array}$ & $\begin{array}{c}1659 \\
(97.9 \%[97.3 \%-98.6 \%])\end{array}$ & $\begin{array}{c}1052 \\
(88.5 \%[86.7 \%-90.3 \%])\end{array}$ & $\begin{array}{c}388 \\
\text { (96.5\% [94.7\%-98.3\%]) }\end{array}$ & $\begin{array}{c}381 \\
(89.4 \%[86.4 \%-92.3 \%])\end{array}$ & $\begin{array}{c}122 \\
(89.7 \%[84.6 \%-94.9 \%])\end{array}$ \\
\hline \multicolumn{6}{|l|}{ Bilateral vision loss } \\
\hline$V A<6 / 12$ to $\geqslant 6 / 18$ & $\begin{array}{c}17 \\
(1.0 \%[0.5 \%-1.5 \%])\end{array}$ & $\begin{array}{c}75 \\
(6.3 \%[4.9 \%-7.7 \%])\end{array}$ & $\begin{array}{c}5 \\
(1.1 \%[<0.1 \%-2.5 \%])\end{array}$ & $\begin{array}{c}24 \\
(5.7 \%[3.4 \%-7.8 \%])\end{array}$ & $\begin{array}{c}9 \\
(6.6 \%[3.0 \%-12.6 \%])\end{array}$ \\
\hline$V A<6 / 18$ to $\geqslant 6 / 60$ & $\begin{array}{c}8 \\
(0.5 \%[0.2 \%-0.9 \%])\end{array}$ & $\begin{array}{c}37 \\
(3.1 \%[2.1 \%-4.1 \%])\end{array}$ & $\begin{array}{c}3 \\
(0.6 \%[<0.1 \%-1.8 \%])\end{array}$ & $\begin{array}{c}10 \\
(2.3 \%[0.9 \%-3.8 \%])\end{array}$ & $\begin{array}{c}5 \\
(3.7 \%[1.1 \%-8.6 \%])\end{array}$ \\
\hline$V A<6 / 60$ to $>P L$ & $\begin{array}{c}3 \\
(0.2 \%[<0.1 \%-0.5 \%])\end{array}$ & $\begin{array}{c}19 \\
(1.6 \%[0.9 \%-2.3 \%])\end{array}$ & $\begin{array}{c}1 \\
(0.2 \%[<0.1 \%-1.2 \%])\end{array}$ & $\begin{array}{c}3 \\
(0.7 \%[0.1 \%-2.1 \%])\end{array}$ & na \\
\hline $\mathrm{PL}$ or $\mathrm{NPL}^{\dagger}$ & na & $\begin{array}{c}3 \\
(0.3 \%[0.1 \%-0.7 \%])\end{array}$ & 0 & $\begin{array}{c}2 \\
(0.5 \%[0.1 \%-1.7 \%])\end{array}$ & na \\
\hline Not recorded & $\begin{array}{c}7 \\
(0.4 \%[0.2 \%-0.9 \%])\end{array}$ & $\begin{array}{c}3 \\
(0.3 \%[0.1 \%-0.7 \%])\end{array}$ & $\begin{array}{c}25 \\
(5.3 \%[3.4 \%-7.8 \%])\end{array}$ & $\begin{array}{c}5 \\
(1.2 \%[0.4 \%-2.8 \%])\end{array}$ & na \\
\hline $\begin{array}{l}\text { Low vision } \\
(V A<6 / 12 \text { to } \geqslant 6 / 60)\end{array}$ & $\begin{array}{c}25 \\
(1.5 \%[0.9 \%-2.1 \%])\end{array}$ & $\begin{array}{c}112 \\
(9.4 \%[7.8 \%-11.1 \%])\end{array}$ & $\begin{array}{c}5 \\
(1.2 \%[0.2 \%-2.3 \%])\end{array}$ & $\begin{array}{c}34 \\
(8.0 \%[5.4 \%-10.6 \%])\end{array}$ & $\begin{array}{c}14 \\
(10.3 \%[5.1 \%-15.5 \%])\end{array}$ \\
\hline $\begin{array}{l}\text { Blindness } \\
(\text { VA < } 6 / 60)\end{array}$ & $\begin{array}{c}3 \\
(0.2 \%[<0.1 \%-0.5 \%])\end{array}$ & $\begin{array}{c}22 \\
(1.9 \%[1.1 \%-2.6 \%])\end{array}$ & $\begin{array}{c}1 \\
(0.2 \%[<0.1 \%-1.4 \%])\end{array}$ & $\begin{array}{c}6 \\
(1.4 \%[0.5 \%-3.1 \%])\end{array}$ & na \\
\hline
\end{tabular}

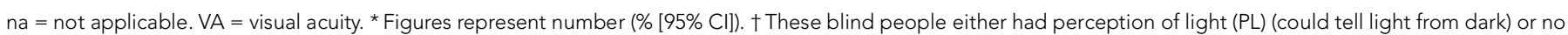
perception of light (NPL) (could not tell light from dark). 
those in all other regions had less vision impairment (both low vision and blindness): odds ratio (OR) (inner regional), 0.58 (95\% CI, 0.20-1.64); OR (outer regional), 0.33 (95\% CI, 0.08-1.27); OR (remote), 0.21 (95\% CI, 0.05-0.80); OR (very remote coastal), 0.25 (95\% CI, 0.07-0.85); OR (very remote inland), 0.06 ( $95 \% \mathrm{CI}, 0.01-0.49$ ). There were no state-based differences seen among children. However, rates of vision impairment in adults were higher in several other states/territories than in NSW: Northern Territory OR, 1.68 (95\% CI, 0.85-3.32); Queensland OR, 2.19 (95\% CI, 1.19-4.03); South Australia OR, 1.72 (95\% CI, 0.803.67); Western Australia OR, 2.29 (95\% CI, 1.26-4.16). (Tasmania and Victoria were omitted because of small numbers.)

Weighted rates of vision loss were agestandardised to the Australian population. ${ }^{14}$ The relative risks (RRs) of low vision and blindness in Indigenous adults compared with mainstream adults were 2.8 and 6.2, respectively (Box 4). ${ }^{16}$ By contrast, in Indigenous children compared with mainstream children the RRs of low vision and blindness were 0.2 and 0.6, respectively (Box 4). ${ }^{17,30,31}$

Both low vision and blindness in adults increased markedly with age (Box 5). Among Indigenous adults over the age of 80 years, $53 \%$ had low vision and 13\% were blind.

\section{Causes of vision loss}

The most common cause of bilateral blindness in Indigenous adults was cataract and the most common cause of low vision was uncorrected refractive error (Box 6). In Indigenous children, uncorrected refractive error was the cause of blindness in one of three children and of low vision in 14 of 25 children. Refractive error was the most common cause of monocular low vision in all groups (Box 7). Ocular trauma was the leading cause of monocular blindness in Indigenous adults.

\section{Near vision}

A third of adults in each of the groups (eligible Indigenous, ineligible Indigenous and non-Indigenous) were unable to read normal-sized print (N8) with their near vision on presentation (Box 8). More nonIndigenous than Indigenous participants wore reading glasses during testing $\left(\chi^{2}=\right.$ 19.0; $P<0.001)$. There was no significant difference in near vision or the use of reading glasses between the three groups. $\left(\chi^{2}\right.$ test $P$ values were between 0.2 and 0.3 ).

\begin{tabular}{|c|c|c|c|}
\hline \multicolumn{4}{|c|}{4 Age-adjusted* prevalence of vision loss } \\
\hline Vision loss & National survey & Mainstream Australia & Relative risk \\
\hline \multicolumn{4}{|l|}{ Low vision } \\
\hline Children $^{\dagger}$ & $1.40 \%(1.38-1.44)$ & $6.36(6.27-6.45)^{\dagger}$ & 0.2 \\
\hline Adults & $14.42(14.39-14.43)$ & $5.19(5.17-5.20)^{\ddagger}$ & 2.8 \\
\hline \multicolumn{4}{|l|}{ Blindness } \\
\hline Children & $0.18(0.17-0.18)$ & $0.28(0.26-0.30)$ & 0.6 \\
\hline Adults & $2.79(2.78-2.81)$ & $0.45(0.44-0.46)^{\ddagger}$ & 6.2 \\
\hline
\end{tabular}

\section{Visual field loss}

Of 1052 participants with presenting VA of $\geqslant 6 / 12,39(3.7 \%)$ missed one FDT point and $96(9.1 \%)$ missed two or more points. In 134 with presenting VA of $<6 / 12,8$ (6.0\%) missed one FDT point and 27 (20.1\%) missed two or more points. The correlation between FDT testing and visual function is not well established, and the prevalence of visual field loss detected by FDT testing has not been determined. ${ }^{32}$

\section{DISCUSSION}

This is the first national report on the vision status of Australian Aboriginal and Torres Strait Islander people for 30 years. Our results confirm the good vision enjoyed by Indigenous children, particularly those in more remote or traditional areas, and reconfirm the high level of avoidable blindness found in adults.

The strengths of our study included its national scope, study design and sampling framework, and the use of a standardised methodology. Its weaknesses included a relatively small sample size, the limited number of sites sampled and somewhat variable participation rate. The absence of a comprehensive ophthalmic examination also limited the ability to establish a definitive diagnosis in every case. In spite of this, there was only one case of vision impairment out of 15 in which a diagnosis could not be reached, and most of these 15 were children for whom retinal photography was not performed.

We were unable to include eligible nonIndigenous adults in all remote and very remote communities. In most very remote communities, the non-Indigenous population was small and transient and, in two remote communities, it was considered inappropriate to examine non-Indigenous subjects. With the very small sample of nonIndigenous adults, only limited comparisons

\section{Age-specific prevalence of visual impairment in eligible Indigenous adults*}

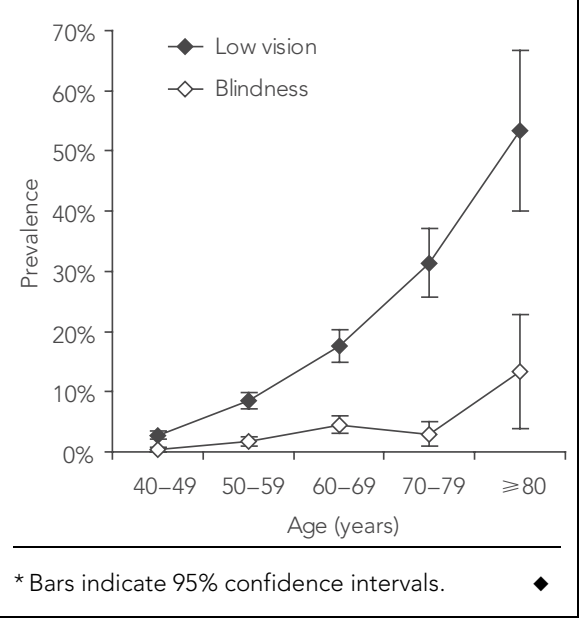

could be made, and no significant differences were found between non-Indigenous adults in our sample and adults in mainstream Australia. ${ }^{16}$

The good vision of Indigenous children can be accounted for by the relative infrequency of myopia, ${ }^{2}$ although the prevalence of myopia may have increased recently. ${ }^{33}$ Nevertheless, uncorrected refractive error was responsible for vision loss in $15 / 28$ Indigenous children (54\%), and only $8 \%$ of Indigenous children wore glasses. Of the 15 Indigenous children with vision impairment due to refractive error, four (27\%) were wearing glasses that were not appropriate and reduced their vision to $<6 / 12$. By comparison, the Sydney Myopia Study found that refractive error caused at least $74 \%$ and possibly $96 \%$ of vision impairment in 6year-olds $^{30}$ and $75 \%$ in 12-year-olds, ${ }^{17,31}$ and that spectacles were worn by $4 \%$ of younger children and 19\% of older children. ${ }^{17,31}$ A detailed comparison between these studies and ours of the prevalence and 


\section{Causes of bilateral vision loss among participants in the National Indigenous Eye Health Survey}

\begin{tabular}{|c|c|c|c|c|c|}
\hline Cause of vision loss & Eligible I & ligenous & Ineligible I & digenous & Non-Indigenous \\
\hline $\begin{array}{l}\text { Low vision } \\
(V A<6 / 12 \text { to } \geqslant 6 / 60)\end{array}$ & $\begin{array}{l}\text { Children } \\
(n=25)\end{array}$ & $\begin{array}{l}\text { Adults } \\
(n=112)\end{array}$ & $\begin{array}{l}\text { Children } \\
(n=5)\end{array}$ & $\begin{array}{l}\text { Adults } \\
(n=34)\end{array}$ & $\begin{array}{l}\text { Adults } \\
(n=14)\end{array}$ \\
\hline Refractive error & $14(56 \%)$ & $60(54 \%)$ & $1(20 \%)$ & $18(53 \%)$ & $5(36 \%)$ \\
\hline Cataract & 0 & 30 (27\%) & 0 & $12(35 \%)$ & $6(43 \%)$ \\
\hline Diabetic retinopathy & 0 & $13(12 \%)$ & 0 & 0 & $1(7 \%)$ \\
\hline AMD & 0 & $2(2 \%)$ & 0 & 0 & 0 \\
\hline Glaucoma & 0 & $1(1 \%)$ & 0 & 0 & $1(7 \%)$ \\
\hline Trachoma & 0 & $2(2 \%)$ & 0 & 0 & 0 \\
\hline Corneal scar & 0 & $1(1 \%)$ & 0 & 0 & 0 \\
\hline Retinitis pigmentosa & 0 & $1(1 \%)$ & 0 & 0 & $1(7 \%)$ \\
\hline Optic atrophy & 0 & $1(1 \%)$ & 0 & 0 & 0 \\
\hline Retinal vascular occlusion & 0 & 0 & 0 & $1(3 \%)$ & 0 \\
\hline Congenital nystagmus & $1(4 \%)$ & 0 & $1(20 \%)$ & 0 & 0 \\
\hline Unknown & $10(40 \%)$ & $1(1 \%)$ & $3(60 \%)$ & $3(9 \%)$ & 0 \\
\hline $\begin{array}{l}\text { Blindness } \\
(V A<6 / 60)\end{array}$ & $\begin{array}{l}\text { Children } \\
\quad(n=3)\end{array}$ & $\begin{array}{l}\text { Adults } \\
(n=22)\end{array}$ & $\begin{array}{l}\text { Children } \\
(n=1)\end{array}$ & $\begin{array}{l}\text { Adults } \\
(n=6)\end{array}$ & $\begin{array}{l}\text { Adults } \\
(n=0)\end{array}$ \\
\hline Refractive error & $1(33 \%)$ & $3(14 \%)$ & $1(100 \%)$ & $1(17 \%)$ & 0 \\
\hline Cataract & 0 & $7(32 \%)$ & 0 & $3(50 \%)$ & 0 \\
\hline Diabetic retinopathy & 0 & $2(9 \%)$ & 0 & 0 & 0 \\
\hline AMD & 0 & 0 & 0 & $1(17 \%)$ & 0 \\
\hline Glaucoma & 0 & 0 & 0 & $1(17 \%)$ & 0 \\
\hline Optic atrophy & 0 & $3(14 \%)$ & 0 & 0 & 0 \\
\hline Ocular trauma & 0 & $1(5 \%)$ & 0 & 0 & 0 \\
\hline Trachoma & 0 & $2(9 \%)$ & 0 & 0 & 0 \\
\hline Retinal detachment & 0 & $1(5 \%)$ & 0 & 0 & 0 \\
\hline Unknown & $2(67 \%)$ & $3(14 \%)$ & 0 & 0 & 0 \\
\hline
\end{tabular}

causes of blindness in children cannot be made because of the very small numbers involved.

Although our study showed that vision impairment was less common in Indigenous than non-Indigenous children, low vision and blindness were much more frequent in Indigenous adults than in mainstream Australian adults, and were the result of different causes. In mainstream Australia, agerelated macular degeneration (AMD) causes $48 \%$ of blindness. ${ }^{16}$ AMD was not seen in our sample population, although one ineligible Indigenous adult was blind from AMD. Similarly, glaucoma, which causes $14 \%$ of blindness in mainstream Australia, ${ }^{16}$ was not seen in our sample population, although one ineligible Indigenous adult was blind from glaucoma. However, optic atrophy and trachoma were common in our study. Our results showed that unoperated cataract was a much more important cause of blindness in Indigenous adults (32\%) than in mainstream Australian adults (12\%), ${ }^{16}$ as was refractive error (14\% in Indigenous adults compared with $4 \%$ in the mainstream). ${ }^{16}$

Similar differences between Indigenous adults and mainstream adults in the causes of low vision were seen. Cataract was a much more common cause of low vision in Indigenous adults (27\%) than in mainstream adults (14\%). ${ }^{16}$ The pattern was similar for diabetic retinopathy $(12 \%$ v $2 \%) .{ }^{16}$ On the other hand, AMD was a less common cause of low vision in Indigenous adults than in mainstream adults (2\% v 10\%).

In 1980, the NTEHP reported 871 blind Aboriginal people out of 10601 over the age of 40 years $(8.2 \%),{ }^{1}$ a rate about 10 times higher than the rate in non-Aboriginal people. The NTEHP rate is much higher than the $2.8 \%$ we found. Detailed comparisons of our study with the NTEHP study are difficult, as their sample was predominantly from more remote areas, their data were aggregated, and their non-Aboriginal sample was self-selected. Nevertheless, some comparison can still be made. In the NTEHP study, ${ }^{1}$ among Aboriginal people aged over 40 years, blindness was caused by corneal disease in $52 \%$ of subjects $(84 \%$ of which was due to trachoma [ie, $44 \%$ of the total]); by cataract in $40 \%$; by diabetes, AMD and other retinal causes in $4 \%$; and by glaucoma in $0.7 \%$. The corresponding data from our study were $9 \%$ for corneal disease (all due to trachoma), 32\% for cataract, 14\% for retinal causes (9\% due to diabetes), and no bilateral blindness due to glaucoma.

Clearly, there has been a major reduction in blindness due to corneal scarring among Indigenous adults since 1980. As there has been no major corneal transplantation program in the intervening years, the reduction in blindness is probably due to the passing of one or more generations of people who were blind from corneal scarring. Rates of cataract-related blindness (40\% in $1980 \mathrm{v}$ $32 \%$ in our study) have not changed significantly.

The rate of self-reported diabetes in Indigenous adults was $0.03 \%$ in the NTEHP study $^{1}$ compared with $37 \%$ in our study. Changes in both lifestyle and diet have been implicated in this increase. ${ }^{34}$ In the NTEHP study, diabetic retinopathy was not separated as a cause of blindness, and all retinal causes, including diabetic retinopathy, caused only $4 \%$ of blindness. We found two out of 22 cases of blindness (9\%) to be due to diabetic retinopathy.

Vision loss in Indigenous adults is predominantly from preventable or treatable causes, and the higher rate of vision loss among Indigenous people reflects a profound underutilisation of eye care services. Without wanting to overinterpret our data, age-specific rates suggest that cataractrelated blindness in adult Indigenous Australians is about 12 times higher than in the mainstream, diabetes-related blindness is over 14 times higher, and blindness due to uncorrected refractive error is over five times higher. Each of these causes of vision loss is readily treatable and preventable.

\section{CONCLUSION}

Over the past 30 years, overall rates of blindness in Aboriginal and Torres Strait Islander people have fallen, especially for blindness due to corneal scarring. However, blindness rates in Indigenous Australians are still much higher than in other Australians, 


\section{Causes of monocular vision loss among participants in the National Indigenous Eye Health Survey}

Cause of vision loss Eligible Indigenous Ineligible Indigenous Non-Indigenous

\begin{tabular}{|c|c|c|c|c|c|}
\hline $\begin{array}{l}\text { Low vision } \\
(V A<6 / 12 \text { to } \geqslant 6 / 60)\end{array}$ & $\begin{array}{l}\text { Children } \\
(n=32)\end{array}$ & $\begin{array}{l}\text { Adults } \\
(n=152)\end{array}$ & $\begin{array}{c}\text { Children } \\
(n=5)\end{array}$ & $\begin{array}{l}\text { Adults } \\
(n=56)\end{array}$ & $\begin{array}{l}\text { Adults } \\
(n=19)\end{array}$ \\
\hline Refractive error & $15(47 \%)$ & 89 (59\%) & $2(40 \%)$ & $29(52 \%)$ & $12(63 \%)$ \\
\hline Cataract & 0 & $28(18 \%)$ & 1 (20\%) & $9(16 \%)$ & $5(26 \%)$ \\
\hline Diabetic retinopathy & 0 & $10(7 \%)$ & 0 & $4(7 \%)$ & 0 \\
\hline Amblyopia & $6(19 \%)$ & $4(3 \%)$ & 0 & $3(5 \%)$ & $2(10 \%)$ \\
\hline AMD & 0 & $3(2 \%)$ & 0 & $2(4 \%)$ & 0 \\
\hline Glaucoma & 0 & $2(1 \%)$ & 0 & 0 & 0 \\
\hline Ocular trauma & 0 & $2(1 \%)$ & 0 & $1(2 \%)$ & 0 \\
\hline Optic atrophy & 0 & $1(1 \%)$ & 0 & 0 & 0 \\
\hline Macular scar & 0 & $1(1 \%)$ & 0 & 0 & 0 \\
\hline Climatic droplet keratopathy & 0 & $1(1 \%)$ & 0 & 0 & 0 \\
\hline Corneal scarring & 0 & 0 & 0 & $1(2 \%)$ & 0 \\
\hline Retinal detachment & 0 & 0 & 0 & $1(2 \%)$ & 0 \\
\hline Congenital coloboma & 0 & $1(1 \%)$ & 0 & 0 & 0 \\
\hline Retinal vascular occlusion & 0 & 0 & 0 & $1(2 \%)$ & 0 \\
\hline Unknown & $11(34 \%)$ & $10(7 \%)$ & 2 (40\%) & $5(9 \%)$ & 0 \\
\hline $\begin{array}{l}\text { Blindness } \\
(\text { VA }<6 / 60)\end{array}$ & $\begin{array}{l}\text { Children } \\
(n=5)\end{array}$ & $\begin{array}{l}\text { Adults } \\
(n=32)\end{array}$ & $\begin{array}{l}\text { Children } \\
(n=2)\end{array}$ & $\begin{array}{l}\text { Adults } \\
(n=16)\end{array}$ & $\begin{array}{l}\text { Adults } \\
(n=2)\end{array}$ \\
\hline Refractive error & $1(20 \%)$ & $3(9 \%)$ & 0 & 0 & 0 \\
\hline Cataract & 0 & 7 (22\%) & $1(50 \%)$ & $5(31 \%)$ & 0 \\
\hline Diabetic retinopathy & 0 & $4(13 \%)$ & 0 & 0 & 0 \\
\hline Amblyopia & $2(40 \%)$ & $1(3 \%)$ & 0 & $3(19 \%)$ & 0 \\
\hline AMD & 0 & $3(9 \%)$ & 0 & 0 & 0 \\
\hline Ocular trauma & 0 & 9 (28\%) & 0 & $6(38 \%)$ & 0 \\
\hline Corneal scarring & 0 & $1(3 \%)$ & 0 & $1(6 \%)$ & $1(50 \%)$ \\
\hline Retinal detachment & 0 & $1(3 \%)$ & 0 & 0 & 1 (50\%) \\
\hline Pterygium/keratoconus & 0 & $1(3 \%)$ & 0 & $1(6 \%)$ & 0 \\
\hline Unknown & $2(40 \%)$ & $2(6 \%)$ & $1(50 \%)$ & 0 & 0 \\
\hline
\end{tabular}

$\mathrm{AMD}=$ age-related macular degeneration. $\mathrm{VA}=$ visual acuity.

\section{Near vision on presentation among adult participants in the National Indigenous Eye Health Survey}

\begin{tabular}{lccc} 
Presenting near vision & $\begin{array}{c}\text { Eligible Indigenous } \\
\text { adults }(n=1189)\end{array}$ & $\begin{array}{c}\text { Ineligible Indigenous } \\
\text { adults }(n=425)\end{array}$ & $\begin{array}{c}\text { Non-Indigenous } \\
\text { adults }(n=136)\end{array}$ \\
\hline Normally wears reading glasses & $725(61 \%)$ & $253(60 \%)$ & $101(74 \%)$ \\
Tested with reading glasses & $515(43 \%)$ & $230(54 \%)$ & $84(62 \%)$ \\
Near vision & $709(60 \%)$ & $247(58 \%)$ & $95(70 \%)$ \\
$\geqslant$ N8* & $436(37 \%)$ & $155(36 \%)$ & $38(28 \%)$ \\
$<$ N8 to $\geqslant N 20$ & $24(2 \%)$ & $11(3 \%)$ & $2(1 \%)$ \\
$<$ N20 to $\geqslant N 48$ & $8(1 \%)$ & $2(<1 \%)$ & 0 \\
$<$ N48 & $12(1 \%)$ & $10(2 \%)$ & $1(1 \%)$ \\
Missing values & & & \\
\hline
\end{tabular}

*N8 means person is able to read normal-sized print with near vision. Higher $\mathrm{N}$ numbers indicate poore vision (ie, larger type size required to distinguish letters clearly). and most blindness is due to readily preventable or treatable causes of vision loss: cataract, diabetes, refractive error and trachoma. Adequate provision of accessible eye care services is required to redress this inequality and "close the gap" for vision loss in Australia.

\section{ACKNOWLEDGEMENTS}

We wish to recognise the contributions of the National Indigenous Eye Health Survey Advisory Committee (Michael Wooldridge, lan Anderson, Sandra Bailey, Stephanie Bell, Joe Chakman, Amanda Davis, William Glasson, Mick Gooda, Elissa Greenham, Belinda Sullivan, Debbie Sweeney) and the Steering Committee (Robert Casson, Rowan Churchill, Mark Gillies, William Glasson, Timothy Henderson, Brian Layland, Mark Loane, lan McAllister, Tharmalingam Mahendrarajah, Richard Mills, Nigel Morlet, Helen Morrissey, Henry Newland, Richard Rawson, Gerd Schlenther). We also thank Mitasha Marolia, Anthea Burnett, Tomer Shemesh, and the many Aboriginal health workers and eye health co-ordinators who assisted with our study (especially Barbara O'Connor, Desley Culpin and Phyllis Tighe), as well as the many volunteers who helped with field work (including Jan Lovie-Kitchen, Nora Ley and Carmel Mclnally).

\section{COMPETING INTERESTS}

Our research was supported by Vision CRC, the International Centre for Eyecare Education, The Eye Foundation and the Harold Mitchell Foundation.

\section{AUTHOR DETAILS}

Hugh R Taylor, AC,MD, FRANZCO, Harold Mitchell Chair of Indigenous Eye Health ${ }^{1,2}$

Jing Xie, PhD, Biostatistician ${ }^{2,3}$

Sarah Fox, BA, Project Coordinator, National Indigenous Eye Health Survey 2,3

Ross A Dunn, BAppSc(AppChem), GradDipBIT, Database Manager ${ }^{2,3}$

Anna-Lena Arnold, BSc, Research Assistant ${ }^{2,3}$ Jill E Keeffe, OAM, PhD, Director of Vision Care Delivery, ${ }^{2}$ and Head, Population Health Unit $^{3}$

1 Melbourne School of Population Health,

University of Melbourne, Melbourne, VIC.

2 Vision Cooperative Research Centre, Sydney, NSW.

3 Centre for Eye Research Australia, University of Melbourne, Melbourne, VIC.

Correspondence: h.taylor@unimelb.edu.au

\section{REFERENCES}

1 Royal Australian College of Ophthalmologists. The National Trachoma and Eye Health Program of the Royal Australian College of Ophthalmologists. Sydney: Royal Australian College of Ophthalmologists, 1980.

2 Taylor HR. Racial variations in vision. Am J Epidemiol 1981; 113: 62-80. 
3 Taylor HR. Prevalence and causes of blindness in Australian Aborigines. Med J Aust 1980; 1: 71-76.

4 Taylor V, Ewald D, Liddle H, Warchiver I. Review of the implementation of the National Aboriginal and Torres Strait Islander Eye Health Program. Canberra: Commonwealth of Australia, 2004.

5 Taylor HR. Eye health in Aboriginal and Torres Strait Islander Communities. Canberra: Commonwealth of Australia, 1997.

6 Mayers N. Report to the Royal Australian College of Ophthalmologists. Sydney: RACO, 1982.

7 Stocks NP, Hiller JE, Newland H, McGilchrist $\mathrm{CA}$. Trends in the prevalence of trachoma, South Australia, 1976 to 1990. Aust N Z J Public Health 1996; 20: 375-381.

8 Mak DB, O'Neill LM, Herceg A, McFarlane H. Prevalence and control of trachoma in Australia, 1997-2004. Commun Dis Intell 2006; 30: 236-247.

9 Jaross N, Ryan P, Newland H. Prevalence of diabetic retinopathy in an Aboriginal Australian population: results from the Katherine Region Diabetic Retinopathy Study (KRDRS). Report no. 1. Clin Experiment Ophthalmol 2003; 31: 32-39.

10 Jaross N, Ryan P, Newland H. Incidence and progression of diabetic retinopathy in an Aboriginal Australian population: results from the Katherine Region Diabetic Retinopathy Study (KRDRS). Report no. 2. Clin Experiment Ophthalmol 2005; 33: 26-33.

11 Lansingh VC, Weih LM, Keeffe JE, Taylor HR. Assessment of trachoma prevalence in a mobile population in Central Australia. Ophthalmic Epidemiol 2001; 8: 97-108.

12 Wright HR, Taylor HR. Clinical examination and laboratory tests for estimation of trachoma prevalence in a remote setting: what are they really telling us? Lancet Infect Dis 2005; 5: 313320.

13 McAllister IL. Screening for diabetic retinopathy in rural and remote areas of Australia. Aust N Z J Ophthalmol 1998; 26: 105-106.
14 Australian Bureau of Statistics. 2006 census. Experimental estimates of Aboriginal and Torres Strait Islander Australians, Jun 2006. (ABS Cat. No. 3238.0.55.001.) http:// www.abs.gov.au/AUSSTATS/abs@.nsf/Lookup/ 3238.0.55.001 Main+Features1 Jun\%202006? (accessed Feb 2010).

15 Fox SS, Arnold A-L, Keeffe JE, Taylor HR. Sampling and recruitment methodology for a national eye health survey of Indigenous Australians. Aust N Z J Public Health 2010. In press.

16 Taylor HR, Keeffe JE, Vu HT, et al. Vision loss in Australia. Med J Aust 2005; 182: 565-568.

17 Robaei D, Huynh SC, Kifley A, Mitchell P. Correctable and non-correctable visual impairment in a population-based sample of 12-year-old Australian children. Am J Ophthalmol 2006; 142: 112-118.

18 Ferraro JG, Mazzoni LL, Keeffe JK, et al. Evaluation of an eye health program: the Vision Initiative. Ophthalmic Epidemiol 2006; 13: 127-135.

19 Mueller A, Vu HT, Ferraro JG, et al. Rapid and cost-effective method to assess vision disorders in a population. Clin Experiment Ophthalmol 2006; 34: 521-525.

20 Burnett AM. Development and validation of a rapid assessment methodology for avoidable blindness in Aboriginal and Torres Strait Islander populations [PhD thesis]. Sydney: University of New South Wales, 2009.

21 Keeffe JE, Lovie-Kitchin JE, Maclean H, Taylor HR. A simplified screening test for identifying people with low vision in developing countries. Bull World Health Organ 1996; 74: 525-532.

22 Thylefors B, Dawson CR, Jones BR, et al. A simple system for the assessment of trachoma and its complications. Bull World Health Organ 1987; 65: 477-483.

23 Taylor HR, Fox SS, Xie J, et al. The prevalence of trachoma in Australia: the National Indigenous Eye Health Survey. Med J Aust 2009; 192: 248-253.

24 Ferraro JG, Pollard T, Müller A, et al. Detecting cataract causing visual impairment using a nonmydriatic fundus camera. Am J Ophthalmol 2005; 139: 725-726
25 Wilkinson CP, Ferris FL, Klein RE; Global Diabetic Retinopathy Project Group. Proposed international clinical diabetic retinopathy and diabetic macular edema disease severity scales. Ophthalmology 2003; 110: 1677-1682.

26 Bird AC, Bressler NM, Bressler SB, et al. An international classification and grading system for age-related maculopathy and age-related macular degeneration. Surv Ophthalmol 1995; 39: 367-374.

27 Constantinou M, Ferraro JG, Lamoureux EL, Taylor HR. Assessment of optic disc cupping with digital fundus photographs. Am J Ophthalmol 2005; 140: 529-531.

28 Robin TA, Müller A, Rait J, et al. Performance of community-based glaucoma screening using frequency doubling technology and Heidelberg retinal tomography. Ophthalmic Epidemiol 2005; 12: 167-178.

29 Foster PJ, Buhrmann R, Quigley HA, Johnson GJ. The definition and classification of glaucoma in prevalence surveys. $\mathrm{Br} \mathrm{J}$ Ophthalmol 2002; 86: 238-242.

30 Robaei D, Rose K, Ojaimi E, et al. Visual acuity and the causes of visual loss in a populationbased sample of 6-year-old Australian children. Ophthalmology 2005; 112: 1275-1282.

31 Robaei D, Kifley A, Rose KA, Mitchell P. Refractive error and patterns of spectacle use in 12 year-old Australian children. Ophthalmology 2006; 113: 1567-1573.

32 Broman AT, Quigley HA, West SK, et al. Estimating the rate of progressive visual field damage in those with open-angle glaucoma, from cross-sectional data. Invest Ophthalmol Vis Sci 2008; 49: 66-76.

33 Taylor HR, Robin TA, Lansingh VC, et al. A myopic shift in Australian Aboriginals: 19772000. Trans Am Ophthalmol Soc 2003; 101: 107112.

34 Daniel M, Rowley KG, McDermott R, O'Dea K. Diabetes and impaired glucose tolerance in Aboriginal Australians: prevalence and risk. Diabetes Res Clin Pract 2002; 57: 23-33.

(Received 23 Jul 2009, accepted 10 Nov 2009) 